\section{Distal esophageal involvement in Crohn disease: short treatment with adalimumab}

The proximal gastrointestinal tract is involved in Crohn disease in less than $4 \%$ of cases [1]. Esophageal involvement occurs in between $0.3 \%$ and $2 \%$ of the total patient population [2]. Upper gastrointestinal involvement is symptomatic or, more rarely, can be asymptomatic, as described by Souza et al. [3].

We report the case of a 49-year-old Italian man who presented with epigastric pain, poor appetite, weight loss, abdominal pain, and diarrhoea. He had already undergone a colonoscopy with retrograde ileoscopy with biopsies, which led to the diagnosis of Crohn disease. Laboratory tests confirmed the active phase of the disease (erythrocyte sedimentation rate $40 \mathrm{~mm} /$ hour, C-reactive protein $27 \mathrm{mg} / \mathrm{L}$ ). Esophagogastroduodenoscopy (EGDS) performed 1 month after the patient's proximal symptoms were first treated with a proton pump inhibitor showed a lesion with a diameter of about $18 \mathrm{~mm}$ at the distal third of the esophageal mucosa ( $\bullet$ Fig. 1).
Histological examination of multiple biopsies showed features compatible with Crohn disease. The patient subsequently underwent pretreatment screening for biological drugs and was given a first injection of adalimumab (Humira) at a dose of $160 \mathrm{mg}$ subcutaneously. A second injection ( $80 \mathrm{mg}$ subcutaneously) was given 15 days later, with subsequent rapid improvement in his proximal symptoms as well as the symptoms related to the ileocecal location. At 3 months after his initial presentation, follow-up EGDS showed a hyperemic mucus lining with healing of the ulcer over a wide area in the distal third of the esophagus ( Fig. 2).

Currently the patient's disease is in remission.

\section{Competing interests: None}

Endoscopy_UCTN_Code_CCL_1AB_2AC_3AZ
D. Musto, L. Martorelli, A. Cirillo, F. Selvaggi, P. Esposito, M. I. Russo, G. Riegler Unit of Gastroenterology and Digestive Endoscopy - IBD Center, Seconda Università degli Studi di Napoli, Napoli, Italy

\section{References}

1 Mottet C, Juillerat P, Pittet $V$ et al. Upper gastrointestinal Crohn's disease. Digestion 2007; 76 Suppl 2: 136-140

2 Lou G-C, Yang JM, Huang W et al. Esophageal Crohn's disease. Endoscopy 2009; 41: E257

3 Souza JLS, da Silva JG, Sipahi AM. Crohn's disease of the esophagus without inflammatory activity confirmed by the use of endoscopy with narrow-band imaging. Endoscopy 2009; 41: E188

\section{Bibliography}

DOI $10.1055 / \mathrm{s}-0030-1255788$

Endoscopy 2010; 42: E299

(c) Georg Thieme Verlag KG Stuttgart · New York . ISSN 0013-726X

\section{Corresponding author \\ D. Musto}

Seconda Università degli Studi di Napoli Unit of Gastroenterology and Digestive Endoscopy, IBD Center

Piazza Miraglia

1 Naples 80138

Italy

Fax: +39-0815665112

dario.musto@alice.it
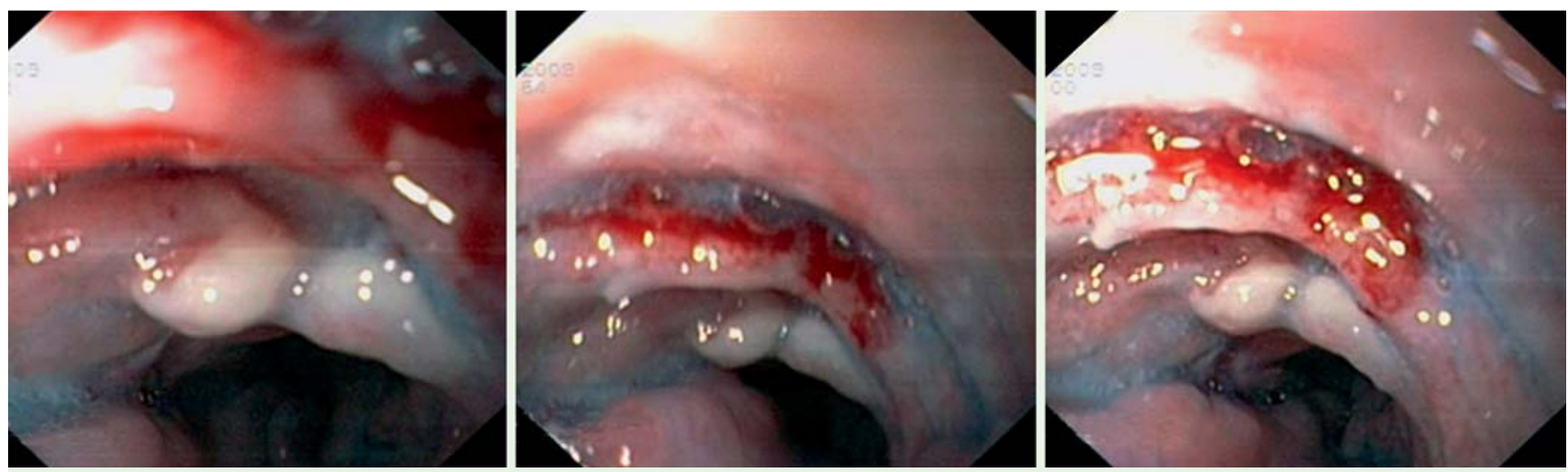

Fig. 1 Pre-treatment esophagogastroduodenoscopy showing the area of ulceration in the distal esophagus.
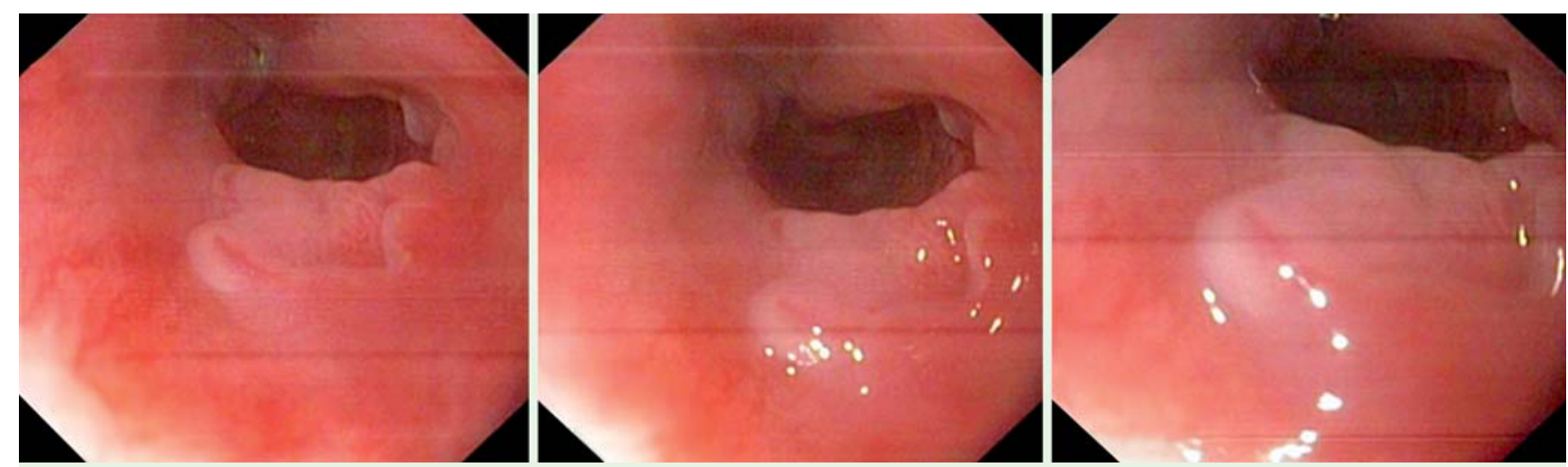

Fig. 2 Post-treatment esophagogastroduodenoscopy showing the healing ulcer. 